\title{
TRATAMENTO DO MELASMA COM PEELINGS QUÍMICOS
}

\section{ARTIGO DE REVISÃO}

BESSA, Vicente Alberto Lima ${ }^{1}$

BESSA, Vicente Alberto Lima. Tratamento do Melasma com Peelings Químicos. Revista Científica Multidisciplinar Núcleo do Conhecimento. Ano 05, Ed. 03, Vol. 07, pp. 05-18. Março de 2020. ISSN: 2448-0959, Link de acesso: https://www.nucleodoconhecimento.com.br/saude/tratamento-do-melasma

\section{RESUMO}

O melasma é uma doença que se caracteriza pelo aparecimento de hipercromia de difícil tratamento. Embora existam vários procedimentos terapêuticos baseados em medicação e terapia física, os peelings químicos ainda são muito utilizados no tratamento do melasma. O presente estudo objetivou descrever o melasma e os tratamentos por meio de peelings químicos. Para tanto, uma revisão do tipo descritiva foi desenvolvida. Constatou-se que vários tipos de peelings têm bons resultados no tratamento do melasma, dentre eles: ácido tranexâmico, ácido ascórbico, ácido retinoico, solução de Jessner combinada com $15 \%$ de ácido tricloroacético, ácido glicólico e o ácido salicílico-mandélico.

Palavras-chave: Melasma, Hyperpigmentation, Pigmentary disorders, Peeling químico.

${ }^{1}$ Especialização em Fisioterapia Dermato-funcional (Unyleya - SP); Graduado em Fisioterapia (UCB - RJ); Tecnólogo em Estética e Cosmética (Celso Lisboa - RJ), Técnico em Estética (IVV - RJ), Professor de Estética Facial do Centro Universitário Celso Lisboa e Centro Universitário do Rio de Janeiro. 


\section{INTRODUÇÃO}

O melasma é um distúrbio de hiperpigmentação adquirido de cor clara a marrom escuro, assintomático, disposto de forma simétrica e com bordas irregulares. Ele pode afetar cerca de $30 \%$ das pessoas de sexo feminino em idade reprodutiva em determinadas populações e pode trazer repercussões na qualidade de vida das pessoas e, por isso, novas estratégia de tratamento têm sido estudadas (PASSERON; PICARDO, 2018). Esse distúrbio é mais comum em mulheres com tipo de pele mais escura e sendo mais insidioso na face. O seu diagnóstico clínico é caracterizado por hipermelanose reticulada simétrica que predomina no centrofacial, malar e mandibular. Porém, há, também, a possibilidade da presença extra-facial do melasma e, neste caso, sua manifestação inclui o pescoço, esterno, antebraços e extremidades superiores (OGBECHIE-GODEC; ELBULUK, 2017).

A etiologia do melasma é multifatorial, pois inclui influências hormonais, fatores genéticos e exposição à luz (OGBECHIE-GODEC; ELBULUK, 2017). Sem embargo, a patogênese dessa disfunção pigmentar ainda não foi inteiramente elucidada (KWON et al, 2016). Contudo, é sabido que a influência da radiação solar pode ser constatada pelo agravamento constante do melasma durante o verão (PASSERON; PICARDO, 2018). Por sua vez, o ser humano precisa ser exposto ao sol para sintetizar vitamina $\mathrm{D}$, além do fato de ser muito difícil não se expor ao sol em países tropicais, como o Brasil. Em vista disso, a exposição ao sol já é um grande empecilho no tratamento do melasma. Embora o melasma seja um distúrbio de pigmentação da pele bastante comum, seu tratamento é difícil (DEL ROSARIO et al, 2017).

Pode-se afirmar que o seu tratamento é altamente desafiador (PASSERON; PICARDO, 2018) e, por muitas vezes, recalcitrante, apesar de ser bem-sucedido (KWON et al, 2016). Em função da sua elevada incidência associada ao incomodo estético e emocional, vários estudos e tratamentos para melasma têm sido propostos. Há procedimentos medicamentosos que envolvem hidroquinona, tretinoina, corticosteroides, ácido tranexâmico, polypodium leucotomos e glutationa, os quais têm tido resultados variados. Não obstante, existem tratamentos estéticos, tais como: peelings químicos, microagulhamento e lasers. Além disso, é possível a combinação 
de terapias que, em geral, têm melhores eficácias do que as monoterapias (OGBECHIE-GODEC; ELBULUK, 2017).

Considerando a variedade de tratamentos, o presente estudo se delimitou ao estudo dos principais peelings químicos empregados no tratamento do melasma. O presente trabalho consistiu numa revisão do tipo descritiva cujo objetivo foi descrever o melasma e os tratamentos por meio de peeling químicos. A fim de desenvolver a pesquisa foram coletadas informações nas bases de dados do Wiley Online Library, Scientific Eletronic Library Online e Science Direct e Europe PMC. Os descritores consultados foram em língua portuguesa e inglesa, sendo eles: melasma (em português e inglês), hyperpigmentation, pigmentary disorders, peeling químico.

\section{REVISÃO DE LITERATURA}

\subsection{MELASMA}

É sabido que o melasma representa uma alteração nos mecanismos de regulação da homeostasia que controlam a pigmentação da pele e, dessa forma, há uma produção excessiva de pigmento (TRIVEDI; YANG; CHO, 2017). Até o momento, a etiologia do melasma não foi totalmente elucidada, porém há vários fatores que desempenham papel importante no seu desenvolvimento, dentre eles: exposição à radiação ultravioleta (UV), disfunções hormonais de estrogênio e progesterona, predisposição genética e/ou processos inflamatórios (KWON et al, 2018; LEE, 2015). Curiosamente, a luz visível penetra até a derme e, junto com o UVA, participa cronicamente no desenvolvimento de lesões de melasma. Concomitanetmente, há evidências que o melasma tem características de um distúrbio cutâneo de fotoenvelhecimento com compomente genético e com influência da irradiação UVA e luz visível (PASSERON; PICARDO, 2018).

Com o advento do exame da lâmpada de Wood, o melasma foi classificado em três tipos: epidérmico, dérmico ou misto, porém um estudo intitulado "A microscopia confocal de reflectância in vivo detecta alterações pigmentares no melasma em uma resolução no nível celular" que confirma que todo melasma é misto. Mesmo assim, o 
uso do exame da lâmpada de Wood continua útil para determinar se a maior parte da pigmentação está na epiderme ou na derme (PASSERON; PICARDO, 2018). Apesar de essa condição ser assintomática e não ter relação evidente com uma doença sistêmica, o aspecto das manchas na pele pode ser prejudicial psicossocialmente aos seus portadores (TRIVEDI; YANG; CHO, 2017). Atualmente, considera-se que o melasma não é apenas uma doença dos melanócitos, mas também um distúrbio do fotoenvelhecimento da pele

Nessa nova perspectiva, o tratamento não seria restrito ao melasma, mas também envolveria condutas anti-aging. Logo, tratamentos convencionais que visam apenas melanossomos ou melanócitos tentem a não ser bem bem-sucedidos, pois a pele fotoenvelhecida entorna dos melanócitos induziria reincidida (KWON et al, 2018). É sabido que a melanina desempenha um papel protetor dos núcleos dos queratinócitos contra a ação deletéria do UV. E esse pigmento é sintetizado no organismo nos melanossomas pelos melanócitos a partir de um mecanismo fisiológico complexo denominado melanogênese. É mister ressaltar que há dois tipos de melanina, feomelanina que tem coloração amarelada ou avermelhada e está presente em pele clara e a eumelanina que tem coloração marrom ou negra e predomina na pele mais escura (VIDEIRA; MOURA; MAGINA, 2013).

Em condições normais, a tirosinase atua no sistema melanogênico. Ela é um complexo enzimático sintetizado nos ribossomos que é transferida por meio do retículo endoplasmático para o Aparelho de Golgi, e posteriormente, armazenada nos melanossomos. E, na presença do oxigênio, a tirosinase converte a tirosina em dopa (dioxifenilalanina) e depois em dopaquinona. A presença ou ausência da cisteína irá determinar o tipo de pigmento de melanina que será sintetizado: feomelanina ou eumelanina. Sem a cisteína, a dopaquinona é convertida em ciclodopa (leucodopacromo) e esta em dopacromo. A degradação do dopacromo pode seguir duas distintas vias de metabolização, uma forma a dopa 5,6 diidroxiindol e outra a 5,6 diidroxiindol-2-ácido carboxílico e este processo é catalisado pelo DOPAcromo tautomerase que resulta na eumelanina. 
Por sua vez, na presença na cisteína, a dopaquinona reage gerando 5-S-cisteinildopa, e, em menor proporção, a 2-S-cisteinildopa, que são oxidadas em benzotiazínicos e, por fim, produzem feomelanina. Os melanossomos acondicionam a melanina e depois injetam o pigmento no interior dos queratinócitos epidérmicos circundantes por meio dos prolongamentos dendríticos dos melanócitos. A proporção entre a mistura de monômeros de feomelanina e eumelanina é quem determinará a expressão fenotípica que caracteriza a cor de pele e cabelo (MIOT et al, 2009). Qualquer mecanismo que gere uma alteração nesse sistema poderá acarretar distúrbios de pigmentação da pele. O melasma é caracterizado pelo aumento da pigmentação da pele como resultado do incremento da atividade dos melanócitos, aumento de melanina nos queratinócitos e deposição dérmica de melanina nos melanófagos perivasculares.

Estudos histológicos encontraram anomalias adicionais no melasma, tais como: aumento da elastose solar, ruptura da membrana basal, aumento do número de mastócitos e aumento da vascularização e, eventualmente, infiltrados linfohistiocíticos perivasculares (OGBECHIE-GODEC; ELBULUK, 2017; KWON et al, 2016). A elastose solar representa um acúmulo de tecido elástico anormal na derme e é um indicador histológico de que há uma alteração da pele promovida pela exposição prolongada ao sol, além de ser um sinal de foto envelhecimento (KWON et al, 2016). Há evidências científicas recentes que sugerem que o melasma pode ser um distúrbio da pele relacionado ao foto envelhecimento que tende acometer as pessoas com predisposição genética (PASSERON; PICARDO, 2018).

O foto envelhecimento desempenha um papel primordial na patogenia do melasma ao interferir, nas citocinas, melanogênicas, e, também, na via de sinalização Wnt, pois a redução do fator inibidor Wnt estimula a melanogênese (KWON et al, 2016). Sabese que o foto envelhecimento é um tipo de envelhecimento extrínseco relacionado aos efeitos cumulativos a exposição aos raios UV que degradam as fibras colágenas e elásticas. É mister ressaltar que o UVA tem comprimento de onda mais longa (320$400 \mathrm{~nm}$ ), logo, penetra profundamente na pele afetando os queratinócitos da epiderme e fibroblastos da derme, mas o UVB tem um comprimento de onda menor (290- 
$320 \mathrm{~nm})$ e, por isso, é mais absorvido pela na epiderme e afeta, prioritariamente, os queratinócitos (FERREIRA, 2019).

Por sua vez, a irradiação UV estimula a melanogênese a partir de efeitos diretos nos melanócitos e indiretos nos queratinócitos ao liberar os fatores melanogênicos (LEE, 2015). Dentre os fatores melanogênicos liberados, têm-se: hormônio estimulador de melanócitos, hormônio adrenocorticotrófico, fator de células-tronco (SCF), fator básico de crescimento de fibroblastos (bFGF), interleucina-1, endotelina-1, óxido nítrico sintase induzível e prostaglandina E2 (PGE2). Esses fatores influenciam na hiperpigmentação da pele (KWON et al, 2016). A ruptura da membrana basal é outra alteração que agrava a condição do melasma e pode ser uma das causas da sua maior reincidiva, pois este evento facilita que os melanócitos caiam na derme, além da deposição da melanina nela (PASSERON; PICARDO, 2018).

Nesse caso, para que o tratamento do melasma tenha efeito, é preciso o emprego de tecnologia para a restauração da membrana basal. Já a exposição crônica a irradiação UV resulta no aumento da vascularização (maior número, tamanho e densidade de vasos) na região do melasma. Também foi constatado que os mastócitos são mais numerosos na pele do melasma do que na pele saudável. Eles liberam VEGF, FGF 2 e TGF - $\beta$ que são fatores angiogênicos, logo, induzem proliferação vascular. Os mastócitos em resposta à irradiação UV também liberam histamina que é um dos fatores de estimulação da melanogênese. Consequentemente, é possível inferir que os mastócitos são primordiais no mecanismo de regulação no desenvolvimento do foto envelhecimento e hiperpigmentação.

Assim sendo, o tratamento antiangiogênico associado ao antienvelhecimento e clareador deve ser considerado (KWON et al, 2018; KWON et al, 2016). A Figura 1 representa um esquema das alterações histológicas no melasma e pode-se constatar que o melanócito aumenta produção de melanina e sua distribuição em todas as camadas epidérmicas. Como a membrana basal está rompida é fácil a migração de melanócitos e melanina para a derme, o que já caracteriza o melasma. Observa-se a presença da elastose solar, além do aumento no número, tamanho e a densidade de vasos sanguíneos e do número de mastócitos na derme. 
Figura 1 - Visão esquemática das alterações histológicas no melasma

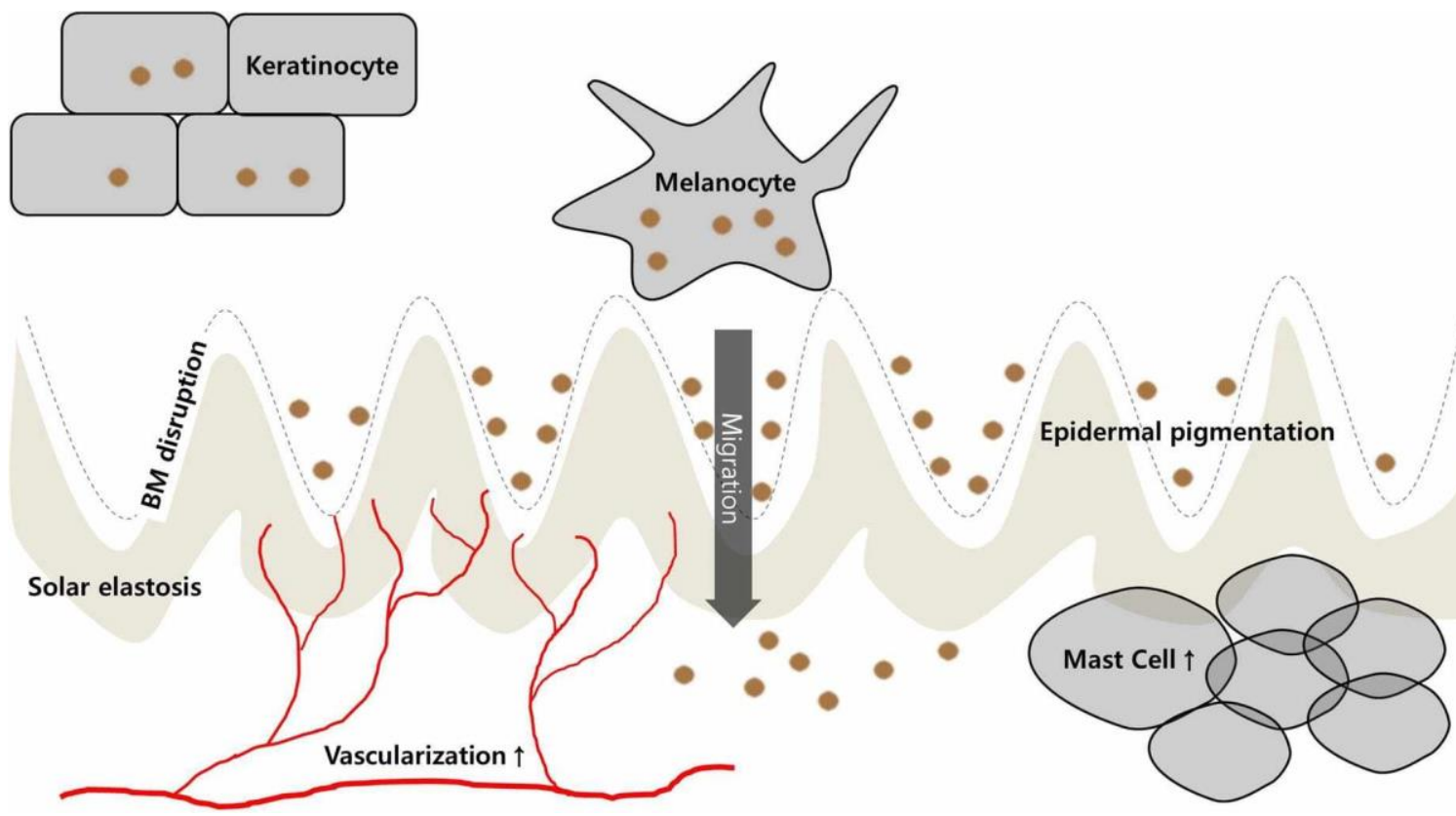

Fonte: Kwon et al (2018, p. 705)

É necessário ressaltar que um estudo utilizando dermatoscópio de epiluminescência digital de alta ampliação, microscopia confocal a laser e exame histológico constatou a presença de lesões vasculares na pele a qual possuía aumento da pigmentação. Nesse estudo, investigou-se o papel das células endoteliais e a influência na pigmentação da pele em um modelo de co-cultura in vitro. Pode-se demonstrar que a endotelina-1 é liberada pelas células endoteliais microvasculares induzem a sinalização da melanogênese que é caracterizada pela fosforilação do fator de transcrição associado à microfoftalmia (MITF) que é o principal fator de transcrição de melanócitos e desempenha um papel no ciclo celular. Outros fatores relacionados à melanogênese dizem respeito ao aumento dos níveis de tirosinase e DOPAcromo tautomerase (REGAZZETTI et al, 2015).

\subsection{QUIMIOESFOLIAÇÃO}

O tratamento com peeling químico também é conhecido como quimioesfoliação. Por sua vez, é sabido que a palavra peeling é de origem inglesa e deriva do verbo to peel que significa descamar, por isso, os procedimentos de peeling objetivam promover 
uma esfoliação da pele. O peeling químico é, basicamente, um ácido que pode ser aplicado de forma tópica na pele a fim de remover, controladamente, as camadas da pele, seguindo-se de um processo de regeneração que permite uma aparência aperfeiçoada. A sua ação pode afetar, em parte, a epiderme ou toda ela e, até mesmo, agir na derme. Portanto, o peeling químico passou a ser classificado em quatro tipos: muito superficial, superficial, médio e profundo, de acordo seu nível de ação.

O peeling químico muito superficial tem uma ação de 0,06mm de profundidade, logo, remove apenas a camada córnea. Já o superficial pode chegar até a camada germinativa, pois sua profundidade chega a $0,45 \mathrm{~mm}$. Os peeling químicos médio e profundo atingem até a derme, sendo que o médio alcança a derme papilar $(0,6 \mathrm{~mm})$, enquanto o profundo atinge a derme reticular média $(0,8 \mathrm{~mm})$. Acredita-se que quanto mais profunda a ação, melhores serão os resultados, porém os riscos aumentam consideravelmente. (YOKOMIZO et al, 2013). É bom lembrar que antes de se aplicar qualquer tipo de peeling químico é necessária uma avaliação criteriosa do cliente para se verificar se há alguma contraindicação ou cuidado especial.

Para se prescrever esse tipo de tratamento alguns critérios devem ser analisados, tais como: estado de saúde geral, idade, fototipo, grau de foto envelhecimento, grau de exposição ao sol, ocupação profissional, medicação em uso, área a tratar e objetivos a alcançar. E vários tratamentos têm sido propostos para o melasma e dentre eles estão: hidroquinona; ácido tranexâmico; ácido retinoico; ácido azelaico; ácido kójico; extrato de belides; extrato de licorice; extrato de emblica (GOES; PEREIRA, 2018). Cada substância interfere em diferentes mecanismos da melanogênese. A hidroquinona (1,4 dihidroxibenzeno), por exemplo, é uma substância derivada do fenol que atua na inibição da tirosinase a partir da ligação com esta enzima ou com as moléculas de cobre.

Dessa forma, a hidroquinona poderia alternar ou até destruir o melanossomo, quiçá até a inibir a síntese de DNA e RNA. Por isso, uma grande preocupação surgiu: o risco de câncer. Todavia, até o presente não foram comprovados efeitos mutagênicos e carcinogênicos da hidroquinona. Mas é sabido que o efeito colateral mais severo seria a ocronose que é uma dermatose que deixa a região na qual foi aplicada a 
hidroquinona com hiperpigmentação negro-azulada fuliginosa. Portanto, a hidroquinona é segura se usada corretamente e sob prescrição do médico (METSAVAHT, 2017). Embora a hidroquinona no tratamento do melasma seja muito prescrita, é sabido de efeitos colaterais, por isso, há alternativas, como o ácido tranexâmico (GOES; PEREIRA, 2018).

Um estudo denominado "Eficácia e possíveis mecanismos do ácido tranexâmico (AT) tópico no melasma" foi desenvolvido e objetivou investigar os efeitos e mecanismo de ação do ácido tranexâmico tópico no tratamento do melasma. Para tanto, 23 voluntárias foram submetidas durante 12 semanas a aplicação na face de uma formulação de AT a $2 \%$. Para avaliar o resultado foi utilizada a escala Melasma Area and Severity Index (Índice de gravidade e área do melasma) e um aparelho denominado chromameter que mensura a coloração da pele. Dez voluntárias foram submetidas à biópsia de pele a fim de examinar a pigmentação, vascularização e níveis de expressão de possíveis fatores parácrinos, os quais colaboram para o efeito do AT. Constatou-se que 22 das 23 voluntárias obtiveram melhora significativa após o tratamento.

O estudo chegou à conclusão de que o AT é eficaz para o melasma e descobriu que a supressão significativa de endotelina-1 seria uma dos mecanismos de ação da AT no melasma (KIM et al, 2016). Esse mesmo ácido foi utilizado em um outro estudo com administração via oral. A pesquisa intitulada "Estudo randomizado, controlado por placebo, duplo-cego, de ácido tranexâmico oral no tratamento de melasma moderado a grave" foi desenvolvida com o objetivo de determinar a eficácia do ácido tranexâmico (AT) oral em pacientes com melasma moderado a grave. Ela foi realizada com 44 mulheres hispânicas voluntárias que possuíam melasma moderado a grave. Um grupo foi tratado com $250 \mathrm{mg}$ de AT e outro com cápsulas de placebo, ambos por duas vezes ao dia por três meses.

Todos usaram protetor solar durante a pesquisa. $O$ acompanhamento foi feito por meio da pontuação modificada do Melasma Area and Severity Index (Índice de Área e Gravidade do Melasma). O resultado do estudo constatou que o AT representou um tratamento promissor e efeitos colaterais mínimos. Apenas 39 das 44 voluntárias 
completaram o tratamento e após três meses o grupo AT teve redução de $49 \%$ no índice contra $18 \%$ no grupo controle, sendo que as voluntárias com melasma grave tiveram melhores resultados que as com melasma moderado (DEL ROSARIO et al, 2017). Para estudar o efeito do peeling de ácido retinoico em pacientes portadoras de melasma, comparando as concentrações de 5 e 10\%, foi realizado um estudo experimental, prospectivo, duplocego e randomizado.

Participaram do estudo 30 voluntários de ambos os sexos com melasma facial e possuíam idade de 25 a 59 anos e fototipo I a V, pela escala de Fitzpatrick. Os participantes foram submetidos aos peelings de ácido retinoico a $5 \%$ ou $10 \%$ segundo o grupo nos quais foram alocados nas semanas $0,2,4,6$. Todos foram orientados a retirar a substância seis horas depois da aplicação e o único procedimento complementar consentido foi o uso de fotoprotetor. Para avaliar o resultado, foi realizada uma avaliação clínica a partir do Melasma Area and Severity Index (MASI) e uma avaliação da qualidade de vida por meio do Melasma Quality of Life Scale (MelasQoL) nas semanas 0 e 8. Os resultados não demonstraram diferença estatística entre os dois percentuais de ácidos e pode-se concluir que ele é eficaz e seguro no tratamento do melasma, como tratamento isolado. Identificou-se poucos efeitos colaterais, como eritema e descamação transitórios no pós-peeling imediato (MAGALHÃES et al, 2011).

Uma pesquisa descritiva primária, longitudinal e experimental foi realizada com o objetivo de verificar a qualidade de vida das voluntárias antes e após o tratamento com peeling químico. Para tanto, dez voluntárias na faixa etária média de 32 anos e com melasma facial foram submetidas ao tratamento Tulipia®. Para avaliar os resultados foi realizada uma anamnese facial, com lâmpada de Wood e Skin Up® Beauty Devices Skin Analyser Digital e, também, a análise fotográfica. As voluntárias também responderam ao Questionário de Qualidade de Vida para Pacientes com Melasma (MelasQoL). Elas foram submetidas ao protocolo de tratamento com ácido ascórbico e do ácido salicílico por um período de três dias consecutivos. Após o tempo necessário para a descamação da pele, uma reavaliação foi realizada. 
Os índices do MelasQoL apresentaram uma melhora significativa indicando uma melhora da qualidade de vida das voluntárias. Houve uma melhora nos níveis de hidratação indicada pela análise dos resultados do skin up®, porém sem resultado expressivo em relação à oleosidade da pele. Confirmou-se que peeling químico aplicado foi eficaz quanto ao clareamento da hipercromia (CHAVES; PEREIRA, 2018). Um estudo para o tratamento do melasma do tipo epidérmico objetivou comparar o efeito terapêutico do ácido tricloroacético combinado (15\%) e a solução de Jessner com $15 \%$ de ácido tricloroacético. Participaram como voluntárias 20 mulheres com idade média de 38,25 anos e fototipo III e IV. Todas foram avaliadas à luz de Wood, Índice de Gravidade e Área Melasma (MASI) e fotografias.

Foi aplicado ácido tricloroacético de $15 \%$ em toda face, exceto no lar esquerdo, no qual recebeu a solução de Jessner combinada com 15\% de ácido tricloroacético. Houve diferença estatística significativa entre o escore MAIS ao se comparar a região malar direita com a esquerda, indicando que a solução de Jessner combinada com $15 \%$ de ácido tricloroacético teve melhor resultado (SAFOURY et al, 2009). Objetivando avaliar três tipos de peeling químicos (ácido salicílico, ácido tricloroacético e ácido glicólico) no tratamento das melanoses faciais (melasma, fotomelanose e pigmentação pós-acne) foi realizado um estudo randomizado, controle cego e paralelo. Participaram do estudo 36 voluntários, sendo 12 com melasma, 12 com fotomelanose e 12 com pigmentação pós-acne.

Cada grupo de 12 foi dividido em 3 subgrupos de 4 componentes para serem submetidos ao peeling com diferentes tipos de ácidos. Um subgrupo foi tratado com peeling de ácido salićlico a $20 \%$ uma vez em 2 semanas, outro com peeling de ácido glicólico a 50\% uma vez em 3 semanas e o último grupo foi tratado com ácido tricloroacético a 15\% uma vez em 3 semanas. Todos os participantes aplicaram obrigatoriamente o filtro solar pós-peeling. Como conduta avaliativa foi realizado o exame da lâmpada de Woods, fotografias no início da terapia e em série e se aplicou um questionário para investigar o estado global de melhoria. Após o final de seis semanas, foi realizada uma reavaliação e os resultados foram: $33,33 \%$ de melhora 
acentuada, 33,33\% de melhora moderada e 33,33\% de melhora leve nos casos de melasma.

O resultado mais otimista em casos de melhora acentuada foi obtido com o ácido glicólico, a melhora moderada foi obtida com o ácido tricloroacético e a melhora leve com o ácido salicílico. Já sobre o tratamento da fotomelanose, 25\% responderam com melhora acentuada com mais eficiência para o ácido tricloroacético, 33,33\% com melhora moderada com mais resultado com o ácido glicólico e 41,66\% com melhora leve, primordialmente com o ácido salicílico. Em relação à pigmentação pós-acne, $25 \%$ dos voluntários responderam com melhora acentuada com mais eficiência para o ácido salicílico, 41,66\% com melhora moderada com mais resultado com o ácido glicólico e ácido salicílico e 33,33\% com melhora leve, especialmente com o ácido salicílico e ácido tricloroacético. Foi concluído que houve um resultado satisfatório nos três tipos de discromias (CHOUDHARY; DHANDE; SINGH, 2017).

Outra pesquisa foi realizada com noventa voluntários e objetivou comparar a eficácia terapêutica e tolerabilidade do ácido glicólico (35\%) versus ácido salicílico-mandélico (20\% salicílico / 10\% de ácido mandélico) versus peeling de combinação fítica em indianos. Os voluntários foram aleatoriamente divididos em três grupos: A, que foi tratado com peeling de ácido glicólico a 35\%, B, com ácido salicílico-mandélico, e C com peeling de combinação fítica. Todos receberam tratamento prévio com $4 \%$ de hidroquinona e $0,05 \%$ de creme de tretinoina por quatro semanas antes do tratamento com peeling. Durante 12 semanas, a cada 14 dias, os voluntários receberam o tratamento com peeling químico. Todos foram submetidos à avaliação clínica e foram fotografados e receberam uma pontuação do Índice de Área e Gravidade do Melasma (MASI) a cada visita e foram acompanhados até 20 semanas.

Pode-se concluir que o peeling de ácido glicólico e o ácido salicílico-mandélico tiveram resposta igualmente eficazes, sendo considerados mais eficientes que o peeling de ácido fítico, além do fato de que o peeling de salicílico-mandélicas ter sido melhor tolerado e mais adequado para a pele indiana (SARKAR et al, 2016). É preciso ressaltar que a quimioesfoliação é indicada quando se objetiva a remoção controlada de camadas da epiderme e/ou da derme a fim de promover uma restauração da pele. 
Além da indicação no tratamento do melasma, o peeling químico também é recomendado para tratar os efeitos do foto envelhecimento, tais como: queratoses, melanoses actínicas, rítides, perda da elasticidade da pele, tratamento de acne ativa e cicatricial. Todavia, há várias contraindicações devido à toxicidade do peeling químico, logo, a sua prescrição deve sempre ser cautelosa.

Há condições em que ele não deve ser utilizado, dentre elas: alergia aos ácidos, em peles sensíveis, pele com ferimentos, cicatrizes de pós-operatório recente, após depilação imediata, herpes zoster, eritema solar, pele inflamada ou com queimaduras de sol, gravidez, lactação, estresse, escoriações neuróticas, fotoproteção inadequada, cicatrização deficiente ou formação de queloide, história de hiperpigmentação pósinflamatória permanente e uso de isotretinoina oral há menos de seis meses (SANTOS et al, 2017). É bom frisar que os tratamentos que priorizam apenas os agentes despigmentantes tópicos isolados não são capazes de restaurar as condições do foto envelhecimento, logo, não têm ação efetiva, pois não corrigem as condições relacionadas ao foto envelhecimento que afetam a melanogênese (KWON et al, 2018). A quimioesfoliação com o tipo correto de agente químico tem a vantagem de poder atuar tanto no clareamento quanto no foto envelhecimento, e, por isso, é um tratamento muito recomendado.

\section{CONSIDERAÇÕES FINAIS}

O melasma é uma doença que se caracteriza pela hipercromia da pele e suas principais alterações histológicas são o aumento da elastose solar, a ruptura da membrana basal, o aumento do número de mastócitos e o aumento da vascularização. Há vários procedimentos de tratamento e dentre eles está o emprego de peeling químico, objeto de investigação deste trabalho. Todavia, deve-se reiterar que o melasma é difícil de ser tratado e possui um grande risco de recidiva, pois sua etiologia é multifatorial. Algumas informações foram bem significativas, tais como a descoberta de que todo melasma é misto. Esse fato pôde ser confirmado pelo estudo via microscopia confocal de reflectância. Outro fato relevante que se deve considerar é que o melasma é um distúrbio do foto envelhecimento da pele. 
Considerando-se que o melasma tem uma relação com o fotoenvelhecimento, tratar o mesmo apenas com agentes despigmentantes não conduziria a bons resultados. Assim sendo, condutas terapêuticas para retardar ou reverter o foto envelhecimento se fazem necessárias. Dentre os peeling que obtiveram respostas satisfatórias na terapia do melasma se destacam os peelings de ácido tranexâmico, ácido ascórbico, ácido retinoico, solução de Jessner combinada com 15\% de ácido tricloroacético, ácido glicólico e o ácido salicílico-mandélico. Porém, em todos os estudos analisados, a amostra foi pequena e variou de 10 até 90 voluntários, com média de 36 voluntários. Logo, as amostras não foram expressivas para se chegar a uma generalização. Recomenda-se, portanto, que novos estudos possam ser desenvolvidos com amostras mais significativas.

\section{REFERÊNCIAS}

CHAVES, J. R; PEREIRA, P. C. Efeitos do Peeling Químico no Tratamento de Melasma: Impacto na qualidade de vida. Revista Científica da FEPI-Revista Científic@ Universitas, v. 5, n. 2, 2018.

CHOUDHARY, S.; DHANDE, S.; SINGH, A. L. Evaluation of various chemical peels in facial melanosis. Indian Journal of Clinical and Experimental Dermatology, v. 3, n. 2, p. 85-87, 2017.

DEL ROSARIO, E. et al. Randomized, placebo-controlled, double-blind study of oral tranexamic acid in the treatment of moderate to severe melasma. Journal of the American Academy of Dermatology, v. 78, n. 2, p. 363-369, out. 2017.

FERREIRA, L. de. A. O uso do ácido lactobiônico na pele fotoenvelhecida. Brazilian Journal of Natural Sciences. v. 2, n. 2, p. 73-79, mai. 2019.

GOES, E. A. F.; PEREIRA, L. L. V. Melasma: diagnóstico e tratamento. Revista Científica, v. 1, n. 1, 2018.

$\mathrm{KIM}, \mathrm{S}$. J. et al. Efficacy and possible mechanisms of topical tranexamic acid in melasma. Clin. Exp. Dermatol., v. 41, p. 480-485, mai. 2016. 
KWON, S. et al. Heterogeneous Pathology of Melasma and Its Clinical Implications. Int. J. Mol. Sci. v. 17, p. 824, 2016.

KWON, S. et al. Melasma: Updates and perspectives. Exp. Dermatol., v. 28, n. 6, p. 704-708, 2018.

LEE, A. Y. Recent progress in melasma pathogenesis. Pigment Cell \& Melanoma Research, v. 28, n. 6, p. 648-660, jul. 2015.

MAGALHÃES, G. M. et al. Double-blind randomized study of 5\% and $10 \%$ retinoic acid peels in the treatment of melasma: clinical evaluation and impact on the quality of life.

Surg. Cosmet. Dermatol., v. 3, n. 1, p. 17-22, 2011.

METSAVAHT, L. O. Hidroquinona: vilã ou heroína? Surgical \& Cosmetic Dermatology, v. 9, n. 3, p. 201-203, 2017.

MIOT, L. D. B. et al. Fisiopatologia do melasma. Anais Brasileiros de Dermatologia, v.8 4, n. 6, p. 623-635, 2009.

OGBECHIE-GODEC, O.; ELBULUK, N. Melasma: an up-to-date comprehensive review. Dermatol Ther (Heidelb), v. 7, p. 305-318, 2017.

PASSERON, T; PICARDO, M. Melasma, a photoaging disorder. Pigment Cell Melanoma Res., v. 31, p. 461-465, jun. 2018.

REGAZZETTI, C. et al. Endothelial cells promote pigmentation through endothelin receptor B activation. Journal of Investigative Dermatology, v. 135, n. 12, p. 30963104, 2015.

SAFOURY, O. S. et al. A study comparing chemical peeling using modified Jessner's solution and $15 \%$ trichloroacetic acid versus $15 \%$ trichloroacetic acid in the treatment of melasma. Indian J Dermatol., v. 54, n. 1, p. 41-45, jan/mar. 2009.

SANTOS, S. L. F. dos. et al. Peelings químicos: contraindicações e complicações dermatológicas. Mostra Científica da Farmácia, v. 2, n. 2, mar. 2017. 
SARKAR, R. et al. Comparative evaluation of efficacy and tolerability of glycolic acid, salicylic mandelic acid, and phytic acid combination peels in melasma. Dermatologic Surgery, v. 42, n. 3, p. 384-391, 2016.

TRIVEDI, M. K., YANG, F. C.; CHO, B. K. A review of laser and light therapy in melasma. International Journal of Women's Dermatology, v. 3, n.1, p. 11-20, 2017.

VIDEIRA, I. F. dos. S.; MOURA, D. F. L.; MAGINA, S. Mechanisms regulating melanogenesis. An. Bras. Dermatol., v. 88, n. 1, p. 76-83, 2020.

YOKOMIZO, V. M. F. et al. Peelings químicos: revisão e aplicação prática. Surg Cosmet Dermatol., v. 5, n. 1, p. 58-68, 2013.

Enviado: Janeiro, 2020.

Aprovado: março 